\title{
Reporting pauses in dramatic dialogue
}

\author{
JULIA C. GARDNER, HEIDI S. MCMILLAN, DARREN TOWNSEND-HANDSCOMB, \\ RICHARD BARRETT-BATES, and DANIEL C. O'CONNELL \\ Georgetown University, Washington, D.C.
}

\begin{abstract}
A total of 55 native speakers of English or German reported occurrence and estimated duration of pauses in both an English and a German performance of an excerpt from Hamlet. A significantly higher percentage of correct reports for the German than for the English performance reflected a slower articulation rate and longer mean duration of actual pauses in the German performance. A significant interaction revealed a much higher percentage of correct reports by native speakers of German for the German performance, but only a negligibly higher percentage by native speakers of English for the English performance. False positive reports of the English performance were more numerous than those of the German performance. Duration estimates of women were consistently longer than those of men for the English performance only. Results are interpreted in terms of a theory of temporal organization of language use.
\end{abstract}

A century ago, William James (1890/1983) bluntly stated that "WE HAVE NO SENSE FOR EMPTY TIME" (p. 583), but added that "empty time is most strongly perceived when it comes as a pause in music or in speech", (p. 589). Today, we still know very little about these "most strongly perceived" empty times in spoken discourse. Presumably, they are perceived as a function of our habits of language use and as a function of the linguistic and physical characteristics of the discourse.

But "listening to discourse" presents an experimental problem. As soon as we call the attention of our subjects to pauses, we draw their attention away from the discourse itself. Requesting subjects to report the occurrence and to estimate the duration of pauses in spoken discourse yields important data regarding linguistic and physical variables; these data may not, however, be considered as directly indicative of what happens in the actual setting of listening to discourse. Pause reports have to do with an artificial situation that can throw light on language use.

For many decades, researchers have persisted in assuming that pause reports of experimental subjects or experimenters themselves correspond veridically to the occurrence of actual intervals of silence. Earlier research in this vein has been critically reviewed by Carpenter and O'Connell (1988). Deese $(1978,1980,1984)$ has insisted that his observers overlooked no pauses and reported none where they did not exist, but reported actual pauses accurately. In other words, they had no false negatives and no false positives, but only hits. Research has now demonstrated that pause reports are subject to both false positives and false negatives (Carpenter \& O'Connell, 1988; Chiappetta, Monti, \& O'Connell, 1987; Duez, 1985; Stuckenberg \& O'Connell, 1988) and therefore cannot be expected to always correspond to actual pause occurrence. This research has been concerned only with monologic

Correspondence may be sent to Daniel C. O'Connell, Psychology Department, Georgetown University, 37th \& O Sts. N.W., Washington, DC 20057. speech and, except for the research of Duez, with oral reading rather than spontaneous speech. Moreover, the specific influences of articulation rate, mean duration of actual pauses, intonation, pitch, (final) syllabic prolongation, loudness, language of the discourse sample listened to, and the language proficiency of the listener still require research.

Stuckenberg and O'Connell (1988) found that Germanspeaking experimental subjects had a higher percentage of hits in English discourse than did English-speaking subjects in German discourse. The reason was found to be the fact that the Germans were proficient in English, but the Amerian subjects were not correspondingly proficient in German. Carpenter and O'Connell (1988) found that transcriptions of a French poem, with poetic format and punctuation, were facilitative for Americans who knew little or no French, but not for native speakers of French. Some researchers have found overestimates of pauses (e.g., Chiappetta et al., 1987) and some have found underestimates of pauses (e.g., Stuckenberg \& O'Connell, 1988).

The goal of the present research is to ascertain how and to what extent the overlearned skills of language use affect these reports, even when the instructions are to attend to the pauses rather than to the communicative content of the discourse. The experiment incorporated a number of elements from the recent studies. Both native American and native German subjects were asked to report pauses in English and German passages in order to confirm the advantage of language proficiency found by Stuckenberg and O'Connell. Presence or absence of punctuation in the transcripts was adopted from the Carpenter and O'Connell research to ascertain whether reports of listeners not proficient in a language would be enhanced by punctuation more than would reports of native listeners. The discourse was dialogic rather than monologic. Between-speaker pauses were expected to be more accurately reported and estimated to be longer than within-speaker pauses. At between-speaker positions where no pause at all occurred, listeners were expected to be particularly prone to report false positives. 
Table 1

Descriptive Statistics for German and English Passages

\begin{tabular}{lcc}
\hline & \multicolumn{2}{c}{ Passage } \\
\cline { 2 - 3 } \multicolumn{1}{c}{ Statistic } & German & English \\
\hline Total time (msec) & 116,560 & 92,015 \\
\% of offtime/total time & 24.00 & 13.75 \\
Speech rate (syl/sec total time) & 2.63 & 3.91 \\
Articulation rate (syl/sec ontime) & 3.30 & 4.54 \\
Mean pause duration (msec) & 646 & 469 \\
Syl/word & 1.48 & 1.24 \\
Syl/phrase (per pause) & 6.96 & 10.59 \\
Time (msec)/phrase (per pause) & 2,018 & 2,334 \\
Words/phrase (per pause) & 4.71 & 8.53 \\
\hline
\end{tabular}

\section{METHOD}

Stimulus materials consisted of an English and a German cassette recording of a section of Act I, Scene 2 of Shakespeare's Hamlet, in which Laertes, the king, Polonius, Hamlet, and the queen all enter into the dialogue (Argo, 158, undated, performed by the Old Vic Company, directed by Toby Robertson; Deutsche Grammophon, 1966, "Die Zeit ist aus den Fugen," Szenen aus Hamlet, Polydor International). Table 1 lists the descriptive statistics for these two samples. These were derived by means of a Siemens Oscillomink $\mathrm{L}$ and an F-J fundamental frequency meter (Type FFM 6502), with a cutoff point of $130 \mathrm{msec}$ for the minimum measurable pause duration.

The articulation rate of each English actor was faster than that of the corresponding German actor (i.e., the player of the same role). Durations of within- and between-speaker pauses did not differ widely in the English (478 and $427 \mathrm{msec}$ ) and German (639 and $666 \mathrm{msec}$ ) samples.

Native English-speaking (14 men, 14 women; mean age $=19$ ) and native German-speaking ( 13 men, 14 women; mean age $=24$ ) subjects were student volunteers from Georgetown University. The Englishspeaking subjects were not proficient in German, but the Germanspeaking subjects were quite proficient in English. The difference constituted a deliberate variation designed to test the relevance of language proficiency in pause reports.

Instructions were presented in English as a typed cover sheet to the English and German transcriptions of the text as follows: "The general objective of this study is to discover the nature of pauses and their role in language. In an effort to do so, we shall examine your responses of pauses with regard to location and duration. In all, you will be presented with two recorded passages: one in English and one in German. In addition, you will be provided with a typed replication of the passage, on which you will record the location and the duration of each pause. You will be presented with each passage four times. For the first two presentations of the passage, please mark with a slash (/) where you believe a pause to exist. Keep in mind that we define a pause as complete silence. For the second two presentations, please record your estimation of the pause duration (e.g., 0.0 seconds). To avoid confusion, we will instruct you immediately before each presentation of the passage."

A second page of instructions traced an example ("To err is human/to forgive divine") through the four steps and explained our use of " 0.0 seconds": to avoid biasing the subjects' judgments of duration one way or another.

The subjects then turned to the transcriptions of the English and German samples, as first one then the other was played four times. Order of presentation was counterbalanced: German-English or EnglishGerman. Half of each group had transcriptions typed with punctuation and capitalization from margin to margin on a single legal-sized sheet of paper; the other half had transcriptions without punctuation and capitalization, but was otherwise the same.

The experimental design therefore consisted of a $2 \times 2 \times 2 \times 2 \times$ 2 factorial. Four of the variables were between subject: men, women; punctuation, no punctuation; German-English and English-German order; German- and English-speaking subjects. The within-subject variable was German and English language of text.

\section{RESULTS}

Significant $F$ s for ANOVAs are reported in Table 2. In all cases, $d f=1,39$. The analysis of duration of pause estimates is for the English text only. An overall analysis inclusive of both German and English texts is not feasible, since the great difference in mean duration of the actual pauses between the two texts $(646-469=$ $177 \mathrm{msec}$ ) excludes a reasonable null hypothesis. The analysis of duration of pause estimates for the German text alone yielded no significant effects.

Percentage of actual pauses reported, rather than number of actual pauses reported, was used as the response measure, because the number of actual pauses was greater in the German text than in the English text $(43>27)$. The main effect of language of text reflects a higher percentage for the German text than for the English text $(87.5 \%>79.8 \% ; S D=15.5$ and 15.0$)$. The significant interaction of language of text $\times$ language of subject indicates that the English-speaking subjects had only a slightly higher percentage than the German-speaking subjects for the English text $(82.5 \%>81.1 \% ; S D=18.1$ and 15.5$)$, and the German-speaking subjects had a much higher percentage for the German text than did the English-speaking subjects $(92.7 \%>78.5 \% ; S D=10.1$ and 14.6$)$. The significant interaction of language of text $\times$ punctuation indicates that no punctuation yielded a higher percentage relative to punctuation for the English text $(82.6 \%>$ $77.1 \% ; S D=10.9$ and 17.9 ), and punctuation yielded a higher percentage than did no punctuation for the German text $(88.3 \%>86.6 \% ; S D=16.5$ and 14.6$)$.

Number of false positives yielded two significant main effects. The language of text main effect reflects a higher number of false positives for the English text than for the German $(10.02>4.00 ; S D=6.95$ and 3.75). The order main effect reflects a higher number of false positives for the German-English order than for the English-German (7.53 > 6.38; $S D=7.57$ and 4.38). The language of subject $\times$ order interaction indicates that the Englishspeaking subjects had a higher number of false positives when the German text appeared first $(9.77>5.50 ; S D$

Table 2

Significant $F$ s in ANOVAs for All Response Measures

\begin{tabular}{lccc}
\hline & \multicolumn{3}{c}{ Response Measure } \\
\cline { 2 - 4 } \multicolumn{1}{c}{$\begin{array}{c}\text { \% of Pauses } \\
\text { Correctly } \\
\text { Reported }\end{array}$} & $\begin{array}{l}\text { Estimates } \\
\text { of Pause } \\
\text { Duration }\end{array}$ & $\begin{array}{l}\text { Number } \\
\text { of False } \\
\text { Positives }\end{array}$ \\
\hline LP & $21.74^{*}$ & & $58.60^{*}$ \\
Order & & & $11.00 \dagger$ \\
Sex & $15.22 \S$ & $4.36 \ddagger$ & \\
LP $\times$ LS & $4.77 \ddagger$ & & \\
LT $\times$ Punctuation & & & $6.93 \ddagger$ \\
LS $\times$ Order & & $7.03 \ddagger$ & \\
LS $\times$ Punctuation $\times$ Sex & & $4.85 \ddagger$ & \\
LS $\times$ Order $\times$ Sex & &
\end{tabular}

Note-Estimates of pause duration were for English passage only. LP = language of passage; $\mathrm{LS}=$ language of subject; $\mathrm{LT}=$ language of text. ${ }^{*} p<.0001 . \quad \dagger p<.005 . \quad \ddagger p<.05 . \quad \$ p<.0005$. 
$=8.38$ and 3.88), whereas the German-speaking subjects had a higher number of false positives when the English text appeared first $(7.33>5.30 ; S D=4.75$ and 6.02).

Duration of pause estimates yielded a significant main effect of sex for the English text only. The women's estimates were longer than the men's $(662>461 \mathrm{msec} ; S D$ $=448$ and 313). Both the punctuation $\times$ sex $\times$ language of subject interaction and the order $\times$ sex $\times$ language of subject interaction are broken out in Table 3 .

\section{DISCUSSION}

In accord with our general hypothesis, the overlearned skills of language use indeed affected these pause reports in an orderly fashion, even though the subjects were under instructions to attend to the pauses, not to the discourse.

The higher percentage of correct reports for the German passage can be ascribed to the fact that the articulation rate is slower and the mean duration of actual pauses longer in the German passage than in the English passage. The English passage may have been additionally misleading in that the percentage of punctuated positions used for actual pauses was considerably less than in the German passage $(58.0 \%<74.1 \%)$ and 6 of 11 between-speaker positions were without pauses. Percentage of correct reports also revealed a significant language of passage $\times$ language of subject interaction that reflected proficiency level: English native speakers were only marginally better than the Germans for the English passage because the Germans were quite proficient in English; but the German native speakers were far better than the Americans for the German passage because the Americans were completely lacking in proficiency in German. This result exactly parallels in the dialogic setting the findings of Stuckenberg and O'Connell (1988) in a monologic setting. The language of passage $\times$ punctuation interaction is accounted for by the above-mentioned discrepancy between percentage of punctuated positions used for actual pauses in the German and English passages.

The significant main effect of language of text in the ANOVA for false positives is evidently contributed to by the fact that six of the betweenspeaker positions in the English passage were without pauses. Inspection of these individual positions confirmed that they did indeed account for many of the false positives in the English passage. The German-English order of presentation yielded significantly more false positives. The reason becomes apparent from the order of presentation $x$ language of subject interaction: When the first passage presented was in the non-native language, more false positives occurred. The effect was greater for the native speakers of English (therefore in the German-English order of presentation) because of their complete lack of proficiency in German.

In both German and English passages, reports of false positives were partly to be accounted for by clustering at positions where there was perceptible prolongation of the preceding final syllable of a word. This has already been noted in the research of Carpenter and O'Connell (1988) and Stuckenberg and O'Connell (1988).

Table 3

Mean (in msec) and Standard Deviations for the Three-Way Interactions in the ANOVA of Estimates of Pause Duration

\begin{tabular}{|c|c|c|c|c|c|c|c|c|}
\hline \multirow[b]{3}{*}{ Condition } & \multicolumn{4}{|c|}{ German Subjects } & \multicolumn{4}{|c|}{ American Subjects } \\
\hline & \multicolumn{2}{|c|}{ Women } & \multicolumn{2}{|c|}{ Men } & \multicolumn{2}{|c|}{ Women } & \multicolumn{2}{|c|}{ Men } \\
\hline & $M$ & $S D$ & $M$ & $S D$ & $M$ & $S D$ & $M$ & $S D$ \\
\hline \multicolumn{9}{|c|}{ LS $\times$ Punctuation $\times$ Sex } \\
\hline $\begin{array}{l}\text { Punctuated } \\
\text { Unpunctuated }\end{array}$ & $\begin{array}{l}723 \\
314\end{array}$ & $\begin{array}{l}352 \\
153\end{array}$ & $\begin{array}{l}330 \\
529\end{array}$ & $\begin{array}{l}182 \\
409\end{array}$ & $\begin{array}{l}661 \\
914\end{array}$ & $\begin{array}{l}253 \\
636\end{array}$ & $\begin{array}{l}562 \\
412\end{array}$ & $\begin{array}{l}381 \\
226\end{array}$ \\
\hline \multicolumn{9}{|c|}{ LS $\times$ Order $\times$ Sex } \\
\hline $\begin{array}{l}\text { German-English } \\
\text { English-German }\end{array}$ & $\begin{array}{l}416 \\
655\end{array}$ & $\begin{array}{l}246 \\
412\end{array}$ & $\begin{array}{l}533 \\
293\end{array}$ & $\begin{array}{l}388 \\
119\end{array}$ & $\begin{array}{l}988 \\
624\end{array}$ & $\begin{array}{l}596 \\
361\end{array}$ & $\begin{array}{l}501 \\
493\end{array}$ & $\begin{array}{l}395 \\
228 \\
\end{array}$ \\
\hline
\end{tabular}

Note-Estimates of pause duration were for English passage only. LS = language of subject.
The significant main effect of sex in the ANOVA of estimates of duration for the English passage alone is difficult to interpret, as are the three-way interactions. However, Figure 1 depicts actual and estimated pause durations across three duration brackets. Stuckenberg and $O^{\prime}$ Connell (1988) found that pause durations were consistently underestimated, with the exception of the estimates in the shortest duration bracket. The pattern that emerges for the German passage is the same, but not for the English passage, wherein the actual pauses themselves are much shorter than in the German passage. It is clear from this comparison that over- or underestimation of durations is partly a consequence of the mean duration of the actual pauses in the passage in question. This explanation obviously does not account for the longer estimates of the English native speakers for the English passage.

The hypothesized differences between within- and between-speaker positions were not confirmed in the present research. Neither in the stimulus materials nor in the subjects' pause reports were there reliable differences in (actual or estimated) durations. Nor was there any evidence of such in the percentages of correct reports and false positives, with the exception that, where there was no pause at a between-speaker position (as happened to be the case at six such positions in the English passage), false positives were consistently reported.

Our findings regarding the influence of punctuation in the present experiment do not parallel those of Carpenter and O'Connell (1988). The language of the passage, rather than the language of the subjects, revealed an interaction with punctuation in the ANOVA of percentage of correct reports. Carpenter and O'Connell's native speakers of English found punctuation of the French text facilitative. But this punctuation condition subsumed poetic format as well. In other words, the punctuated format was in poetic lines. No such format is present in the passages used in our research, and so it is not at all surprising that no language of subject $\times$ punctuation interaction emerged.

But beyond all these individual sensitivities of subjects to articulation rates, native and non-native languages, mean duration of pauses, and a variety of positional characteristics, there remain even more important questions. What is it, overall, that determines such behavior in a listener? Why is it that, even though instructed to process pauses (empty time) rather than the content of the discourse, subjects seem unable to rid themselves of the misleading cues associated with language use?

The findings of the present research and of other recent research involving pause reports can be handily integrated under the aegis of Hörmann's $(1981,1986)$ conceptualizations of meaning. Unlike many current semantic theories, Hörmann's is an endeavor to comprehend the search for meaning - both in formulation, on the part of a speaker, and in perception, on the part of a listener. In the present instance, we are dealing with subjects who might well be described as unwilling searchers for meaning. Once the conventions of language use have been invoked (in the present case, by the presentation of the dialogic passages in two natural languages recognizable as such by the listeners), the subjects cannot but anticipate meaning and become involved in a search for meaning at some overlearned and nonreflective level. This is precisely what Innis (in Hörmann, 1986) means when he refers to "the primacy of function over form, that is of meaning over syntax, and a continual awareness of the steering function of language, with both the speaker's and the hearer's consciousness being steered by the linguistic tools"' (p. 17). This primacy partly depends "on the interest structures of the language user's consciousness" (p. 18).

This search for, or preoccupation with, meaning-this insistence on making linguistic usage as intelligible as possible-is what Hörmann has referred to as Sinnkonstanz or "meaning constancy," man's "incessant striving to make the world and all events around him intelligible' (Hörmann, 1981, p. 308).

This is not to say that meaning constancy will always succeed in accomplishing a higher percentage of correct reports. Duez (1985), in fact, found a very high rate $(85 \%$; p. 382$)$ of correct pause reports in a strictly psychoacoustic task with synthetic speech that had been radically simplified. In some settings, real meaning can distract from the primitive physical dimensionality of a given input. This is evidently what happens in the case of the between-speaker positions where there are no pauses, but where false positives are consistently reported.

Our preoccupation with temporal organization in language use is not an end in itself. Measurements of linear time are to be subordinated to what James $(1890 / 1983)$ referred to as "expecting, and being ready 


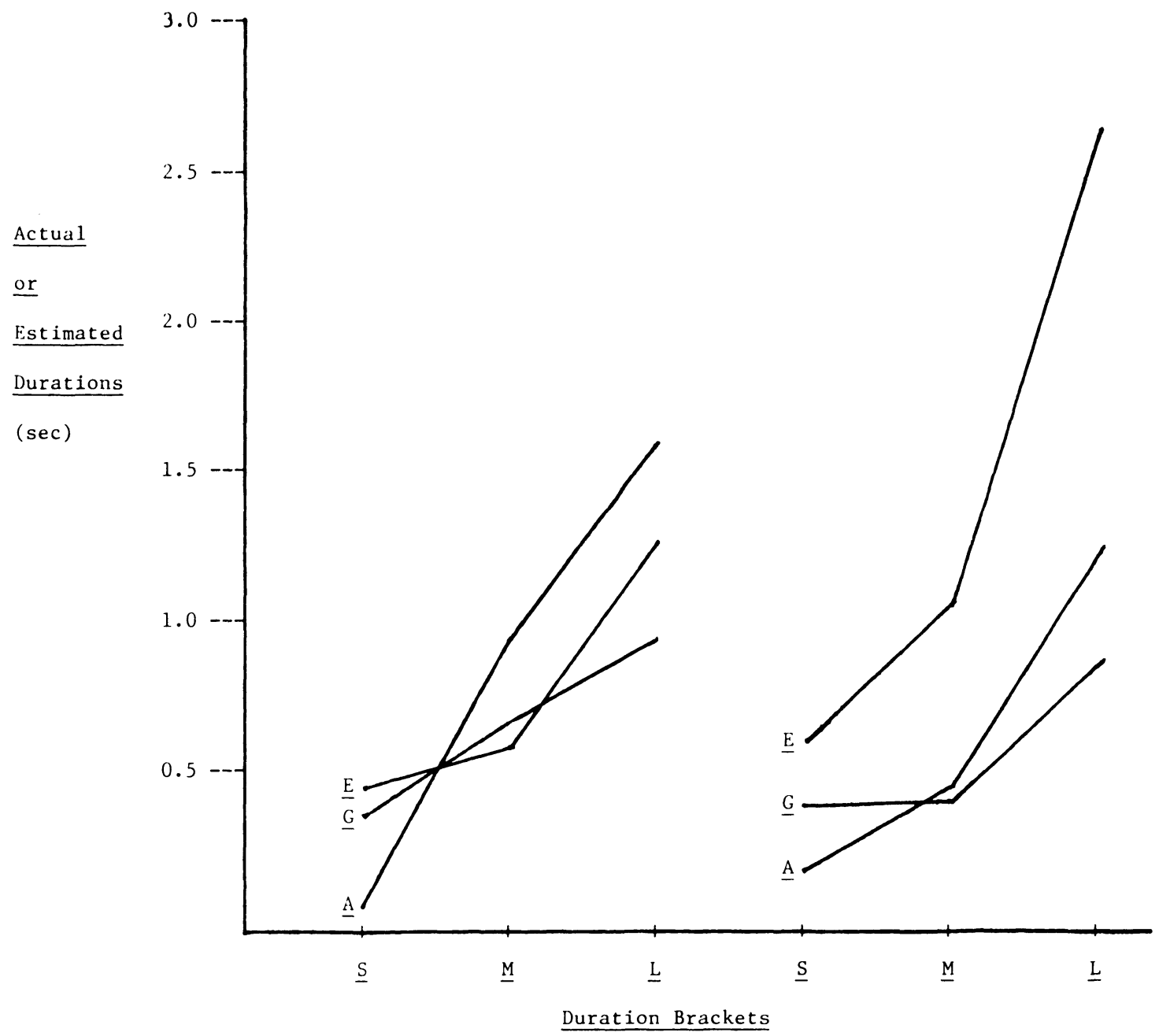

Figure 1. Actual $(A)$ pause durations within short $(\leq 0.3 \mathrm{sec}$, or $S)$, medium $(>0.3,<1.0 \mathrm{sec}$, or $M)$, and long $(\geq 1.0 \mathrm{sec}$, or $L)$ brackets for German and English passages, and corresponding estimates by native speakers of American English $(E)$ and German $(G)$.

for a new impression to succeed" (p. 589). This anticipation is precisely what constitutes a subject's psychological sense of time in the present experimental settings, and it is this interfacing with psychological time that is ultimately of importance. A theory of temporal organization of language use ultimately has to do not with physical or linear time, but with psychological time. The two are closely related, but not at all the same; we use the former as a stepping stone to the latter.

The present results clearly extend the findings of Stuckenberg and O'Connell (1988) beyond a monologic to a dialogic setting. They indicate even more clearly than the other recent research that language processing is not limited to settings where meaning can be found, but extends to settings where meaning cannot but be sought by reason of our overlearned language skills. The search for meaning thus provides a key conceptual framework for further research.

\section{REFERENCES}

Carpenter, S., \& O'Connell, D. C. (1988). More than meets the ear: Some variables affecting pause reports. Language \& Communication, 8, 17-27.

Chiappetta, J., Monti, L. A., \& O’Connell, D. C. (1987). Pause perception: Some cross-linguistic comparisons. Bulletin of the Psychonomic Society, 25, 103-105.

DEESE, J. (1978). Thought into speech. American Scientist, 66, 314-321. DeESE, J. (1980). Pauses, prosody, and the demands of production in language. In H. W. Dechert \& M. Raupach (Eds.), Temporal variables in speech: Studies in honour of Frieda Goldman-Eisler (pp. 6984). The Hague: Mouton.

DEESE, J. (1984). Thought into speech: The psychology of a language. Englewood Cliffs, NJ: Prentice Hall.

DuEz, D. (1985). Perception of silent pauses in continuous speech. Language \& Speech, 28, 377-389.

Hörmann, H. (1981). To mean-to understand: Problems of psychological semantics (D. A. Jankowski, Trans.). Berlin: Springer-Verlag. HörmanN, H. (1986). Meaning and context: An introduction to the psychology of language (R. E. Innis, Ed.). New York: Plenum.

JAMES, W. (1983). The principles of psychology. Cambridge, MA: Harvard University Press. (Original work published 1890)

Stuckenberg, A., \& O'ConNell, D. C. (1988). The long and the short of it: Reports of pause occurrence and duration in speech. Journal of Psycholinguistic Research, 17, 19-28.

(Manuscript received September 7, 1989.) 